\title{
Simplified finite element model for evaluation of ultimate capacity of corrosion-damaged reinforced concrete beam-columns
}

\author{
A. Mohammed ${ }^{1} \cdot$ H. Almansour ${ }^{1} \cdot$ B. Martín-Pérez ${ }^{2}$
}

Received: 5 October 2017 / Accepted: 5 October 2018 / Published online: 31 October 2018

(c) The Author(s) 2018

\begin{abstract}
A simplified nonlinear finite element analysis (NLFEA) based on enhanced inspection, material testing, and nonlinear sectional analysis is introduced as part of a semi-quantitative assessment approach of aged beam-columns. The focus is on the evaluation of the structural performance and residual capacities of slab-on-girder bridge columns subjected to combined external loads and reinforcement corrosion. NLFEA takes into account different levels of geometrical, material, and bond damage due to reinforcement corrosion. At each load step of the nonlinear analysis process, NLFEA establishes the instantaneous stiffness of the structure through effective transfer of the instantaneous axial and flexural rigidities from the sectional level to the element level. The model adopts a displacement field tuning convergence approach that involves single or multiple correction phases satisfying the equilibrium and any user-defined displacement tolerance. The efficiency and accuracy of the proposed NLFEA is verified by comparison with test and analytical results from previous studies conducted on undamaged and corrosion-damaged structural elements. NLFEA proves to have high numerical stability and fast convergence, establishing its adoptability in large structural analysis/assessment frameworks. For corrosion-damaged beamcolumns, it is found that critical design sections do not necessarily remain critical for the structural evaluation.
\end{abstract}

Keywords Nonlinear finite element analysis $\cdot$ Reinforcement corrosion $\cdot \mathrm{RC}$ bridge column $\cdot$ Semi-quantitative assessment framework $\cdot$ Displacement field tuning convergence

\section{Introduction}

A significant percentage of North American infrastructure, specifically bridges, are reported deficient (Lounis et al. 2010), while limited public resources are available for their maintenance/rehabilitation. The qualitative assessment approaches adopted by different states in the US or different provinces in Canada are based on periodic visual inspections (usually every 2 years). With variable inspectors'

A. Mohammed

amina.mohammed@nrc-cnrc.gc.ca

H. Almansour

husham.almansour@nrc-cnrc.gc.ca

B. Martín-Pérez

beatriz.martin-perez@uottawa.ca

1 Civil Engineering Infrastructure, National Research Council Canada, 1200 Montreal Road, Building M-20, Ottawa, ON K1A 0R6, Canada

2 University of Ottawa, CBY A306, 161 Louis Pasteur, Ottawa, ON K1N 6N5, Canada experience, it is difficult to have an accurate rating of the bridge status, where an evaluation of the residual ultimate and service capacities of a critical bridge is not performed. When a bridge is identified as deficient and its load capacity is questionable, a simplified evaluation approach, if available, can help practicing engineers and bridge owners to have a better quantitative base for their management decisions. The increasing gap between the deterioration demand and available resources raises the need to develop a practical yet efficient quantitative assessment (evaluation) framework (QAF). The development of such an evaluation approach requires the development of accurate structural analysis models that are capable to estimate both the time-dependent deterioration of ultimate capacities of critical bridge elements as well as the bridge allowable service loads.

Most of North American bridge infrastructure that was built during the development boom from the 1950s to 1970s has different levels of deterioration, and their safety and serviceability are susceptible. Present infrastructure management systems mainly rely on qualitative evaluation approaches, where the bridge structural performance 
status is judged through routine visual inspection (usually every 2 years). If a "severe" deterioration case is captured, more refined inspection is conducted. The bridge management systems (BMS) in North America and many other countries around the world are based on identification of four general condition states under which the bridge elements are categorized. The four condition states are (1) Excellent, (2) Good; (3) Fair; and (4) Poor (see Ministry of Transportation 2008 and American Association of State Highway and Transportation Officials 2007). The accuracy of bridge rating and management decisions of bridge engineers reliy on the accuracy of the bridge condition assessment (Rashidi and Gibson 2012), mainly based on different levels of visual inspection. Different bridge management systems recognize many types of visual inspection such as the typical visual inspection (VI), in-depth VI, and enhanced in-depth VI (see FHWA-RD-01-020, Ministry of Transportation 2008 and American Association of State Highway and Transportation Officials 2000). The comparison of bridge inspection standards among various international organizations indicates that each organization has a different approach to bridge inspection in terms of the types of inspection, the frequency of the inspections, the definition of the various inspection types, and the type of personnel that undertakes the inspections (Brown et al. 2010). The lack of a practically simple and cost-effective quantitative assessment approach that is capable to accurately determine the state of the performance in terms of safety and serviceability of critical bridge elements is now identified as a major research gap.

Reinforcement corrosion has been identified as the major cause of the deficiency of structural capacity and ductility of reinforced concrete (RC) infrastructure. The initiation and progression of corrosion in reinforcing steel can have unlimited number of scenarios that are yet not fully understood. It is very challenging to develop time-dependent analytical models that are capable to accurately estimate the effects of all different reinforcement corrosion scenarios on the structural behavior of damaged RC elements. Instead, a simplified and practical semi-quantitative assessment (evaluation) framework (SQAF) can be developed. Visual inspection enhanced with some measurements of the damage zones and selected material testing can provide a relatively accurate data for the SQAF. In the absence of enough test results, empirical formulae can be used to estimate the material properties of the steel and the related level of damage. The SQAF should address the major evaluation limit states of corrosion-damaged bridge elements that are consistent with existing bridge design codes: ultimate limit state (ULS) including seismic loads (for high risk zones), and serviceability limit state (SLS) (Canadian Standards Association (2006), or American Association of State Highway and Transportation Officials 2007).
The advances in experimental investigation enable better understanding of the damage and failure mechanisms of RC structures under extreme external loads (Mohammed 2014). The objective of this paper was to present the development of a simplified non-linear finite element analysis approach (NLFEA) to simulate the structural behavior of corrosiondamaged RC elements. The input data for the NLFEA come from an inspection enhanced with some measurements and material testing, whereas the nonlinear finite element approach is based on the nonlinear sectional analysis developed by the authors (Mohammed 2014). The inspection provides input data about the location and size of the damaged zone and the level of damage, while material testing enables the evaluation of the instantaneous material properties at the time of the assessment. NLFEA can serve as the basis of the SQAF, where the aged/damaged bridge load capacity can be estimated. The focus of the study is on the structural behavior of aged bridge beam-column elements such as: (1) the columns are the most critical elements for the stability and robustness of bridge structures; and (2) beam-column elements are the most general frame elements that simulate the behavior of beams, columns, or beam-columns, and hence they can be adopted in modeling buildings as well (e.g., parking garages).

This NLFEA requires the use of an efficient elasto-plastic nonlinear model that takes into account different levels of geometrical, material, and bond damage due to reinforcement corrosion at the section level. In order to establish the instantaneous element stiffness, and hence the global stiffness of the structure at each load step, the instantaneous axial and flexural rigidities at the sectional level are to be effectively transferred to the element level in the NLFEA. Furthermore, the NLFEA has to safely match the available experimental and/or field test results for the case of external loading without corrosion and for the case of combined load and reinforcement corrosion. However, it has to be simple, numerically stable, and able to be integrated into the proposed SQAF procedure:nonlinear finite element analysis (NLFEA) as a part of proposed semi-quantitative assessment framework (SQAF).

The proposed SQAF (see Fig. 1) has six parts: (1) input data; (2) quantification of reinforcement corrosion and its effects on the damage zone and materials' properties; (3) evaluation-ULS: evaluation of columns' performance under combined corrosion and ultimate loads; (4) evaluation-SLS: evaluation of columns' performance under combined corrosion and traffic loads; (5) evaluation-ULS-EQ evaluation of columns' performance under corrosion and ultimate seismic loads as part of evaluation-ULS, only in high-risk seismic zones, (Canadian Standards Association 2006) (CAN/CSAS6-14); and (6) semi-quantitative assessment and reporting. The NLFEA plays the most important role in the proposed SQAF. It performs the three major parts of the evaluation: 


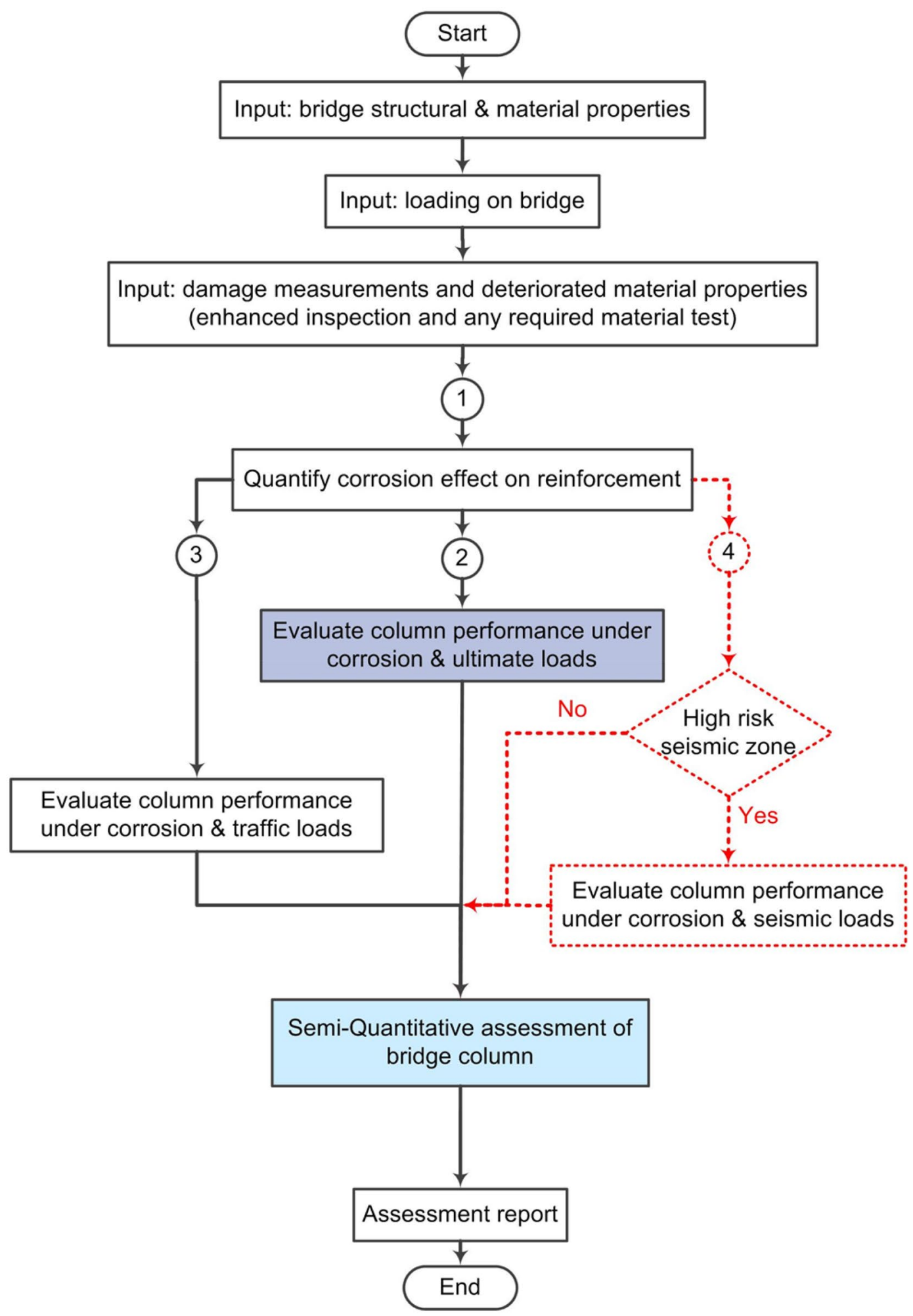

Fig. 1 The proposed SQAF of aging RC bridge columns

evaluation-ULS and evaluation-ULS-EQ (part III and part V), and evaluation-SLS (part IV). The evaluation of the column structural performance under combined reinforcement corrosion and traffic loads and the evaluation of the column structural performance under combined reinforcement corrosion and seismic loads are presented by Mohammed (2014). 
It has to be noted that the fatigue limit state (FLS) is considered as out of the scope of this study.

The first part of the proposed SQAF includes three datainput tasks: (I-a) the structural material and geometrical data including boundary conditions; (I-b) the loading data; and (I-c) the enhanced inspection data (reinforcement corrosion damaged zones). In the first task, the data are collected from the original design information/sketches (if available) and the field tests on the materials (if possible). The difference between the original design loads and the present loads on the bridge column under consideration is to be determined. The enhanced inspection can provide very important measurements and details that can identify the state of corrosionaffected or -damaged zones. The deterioration of the structural parameters is then re-evaluated quantitatively through the NLFEA as shown in the following sections.

The proposed SQAF identifies four major damage cases due to the reinforcement corrosion, as shown in Fig. 2: (II-a) corrosion concrete cracking; (II-b) concrete cover spalling (number 5 in Fig. 2); (II-c) failure of one or more stirrups (number 6 in Fig. 2); and (II-d) a more advanced state of corrosion progress that would lead to the structural failure through complete loss of the confinement or rebar buckling (number 7 in Fig. 2). The details of each of these major possible deterioration states are shown in Fig. 2.

The ULS is interactively integrated with step (II) above, where at each major corrosion effect case; the flowchart shows an end-link to the NLFEA (see Fig. 2). For instance, NLFEA is the basis of four evaluation-ULS tasks: (III-a) establishing the load-displacement relationship; (III-b) establishing the moment-curvature relationship; (III-c) evaluating the load capacity deterioration compared to the state of no damage; and (III-d) evaluating the structural ductility deterioration. These four tasks of evaluation-ULS end with the preparation of the required data for the SQAF.

\section{Modeling the effects of reinforcement corrosion at the element level}

Reinforcement corrosion can lead to different damage mechanisms in the steel and the surrounding concrete in the affected zones. Corrosion-induced damage results in significant change of the concrete and steel strength and ductility, deterioration of the composite action and integrity at the section level, and hence a reduction in the axial and flexural stiffnesses. If local damage affects a critical flexural or shear zone, the structural capacity of the RC element based on sectional analysis can significantly decrease. In this paper, the investigation on the effects of reinforcement corrosion on the structural behavior is for overall structural-element level and comprehensively integrates these effects into the NLFEA.

In order to present the combined effects of reinforcement corrosion (with the possible damages) and external loads into the proposed nonlinear finite element approach, Fig. 3 shows a beam-column element subjected to axial force and bending moment. Figure 3 a shows a possible general loading, boundary condition, and reinforcement of a beam-column element. In most practical cases, bridge columns are subjected to eccentric axial loads, where flexural cracks form at the maximum moment zone. If the external moment is constant over the column height and the axial load is dominant (no tensile stress is developed on any section along the beam-column), then no flexural cracks would develop. However, the high axial load could result in cracks due to lateral expansion (Poisson's ratio effect). The bridge columns are conservatively designed for a lower bound service-to-ultimate loads ratio; hence service to ultimate load capacity of columns is in the range of $25-50 \%$. If the external moment is high enough to generate tensile stresses in one of the column side faces, then flexural cracks develop laterally parallel to each other and distributed over the column height. When reinforcement corrosion is initiated over the main reinforcement, as shown in Fig. 3b, then corrosion cracks could develop parallel to the rebars, crossing flexural cracks. An accelerated cover spalling could take place if both cracks are developed at the same time. If corrosion continues to progress, more longitudinal cracks can develop, and the local corrosion damage of the surrounding concrete could lead to local loss of bond followed by spalling of the concrete cover as shown in Fig. 3c. In addition, uniform loss of the reinforcement cross-sectional area over the corrosion-damaged zone takes place. The properties of the steel also change with the progress of corrosion. It has to be noted that the case of local severe reduction of the cross-sectional area of some rebars due to pitting corrosion is not discussed in this study. The mentioned changes could result in a large decrease of the axial and flexural sectional rigidities. Further progress of the corrosion process could result in some stirrups failure (rebar fracture), as shown in Fig. 3d, and this would increase the local spacing between the lateral ties. This would result in a reduction of the confinement of the core concrete, and hence the overall stiffness and strength of the column, specifically in the critical damaged zones, would be reduced. In relation to the finite element discretization, three types of elements are distinguished in beam-columns with local corrosion damage: (1) no-corrosion damaged zone; (2) partly corrosion damaged or corrosion-transition zone; (3) fully corrosion damaged zone (see Fig. 3e).

\section{Reduction in reinforcement cross-sectional area and ductility, and loss of concrete cover}

The changes in geometrical properties of the corrosion-damaged zones and in the materials properties of the steel and the concrete at the section level are shown by Mohammed (2014). Each element in the finite element analysis at the 


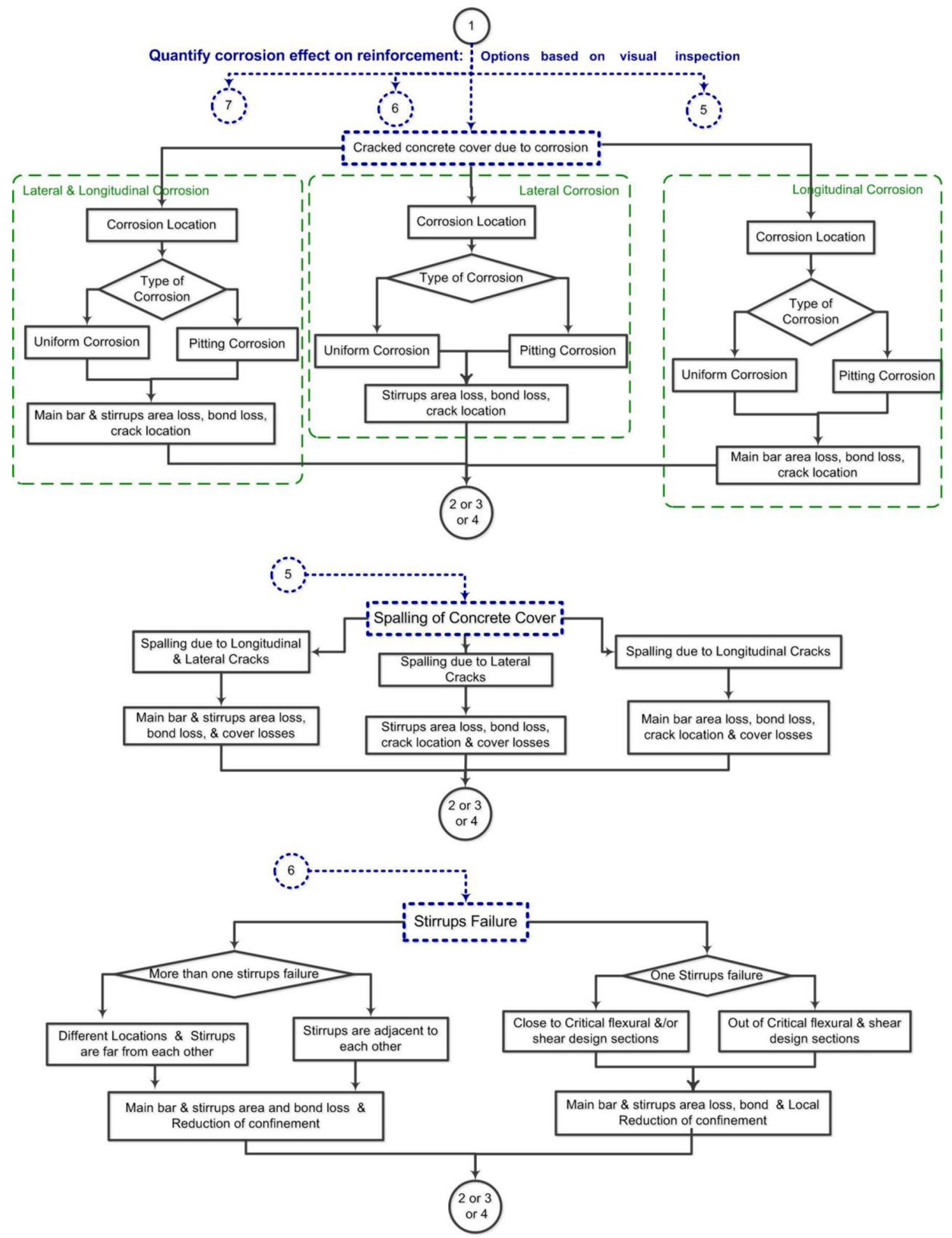

Fig. 2 Evaluation of column performance under corrosion and ultimate loads. Evaluation of column performance under corrosion and ultimate loads

structural level has its geometrical and material properties as the average properties of its characteristic sections that are evaluated at the sectional level. The instantaneous element stiffness estimated at each load step is based on the equivalent average of the axial rigidities and the equivalent average of the flexural rigidities of all characteristic sections of that 

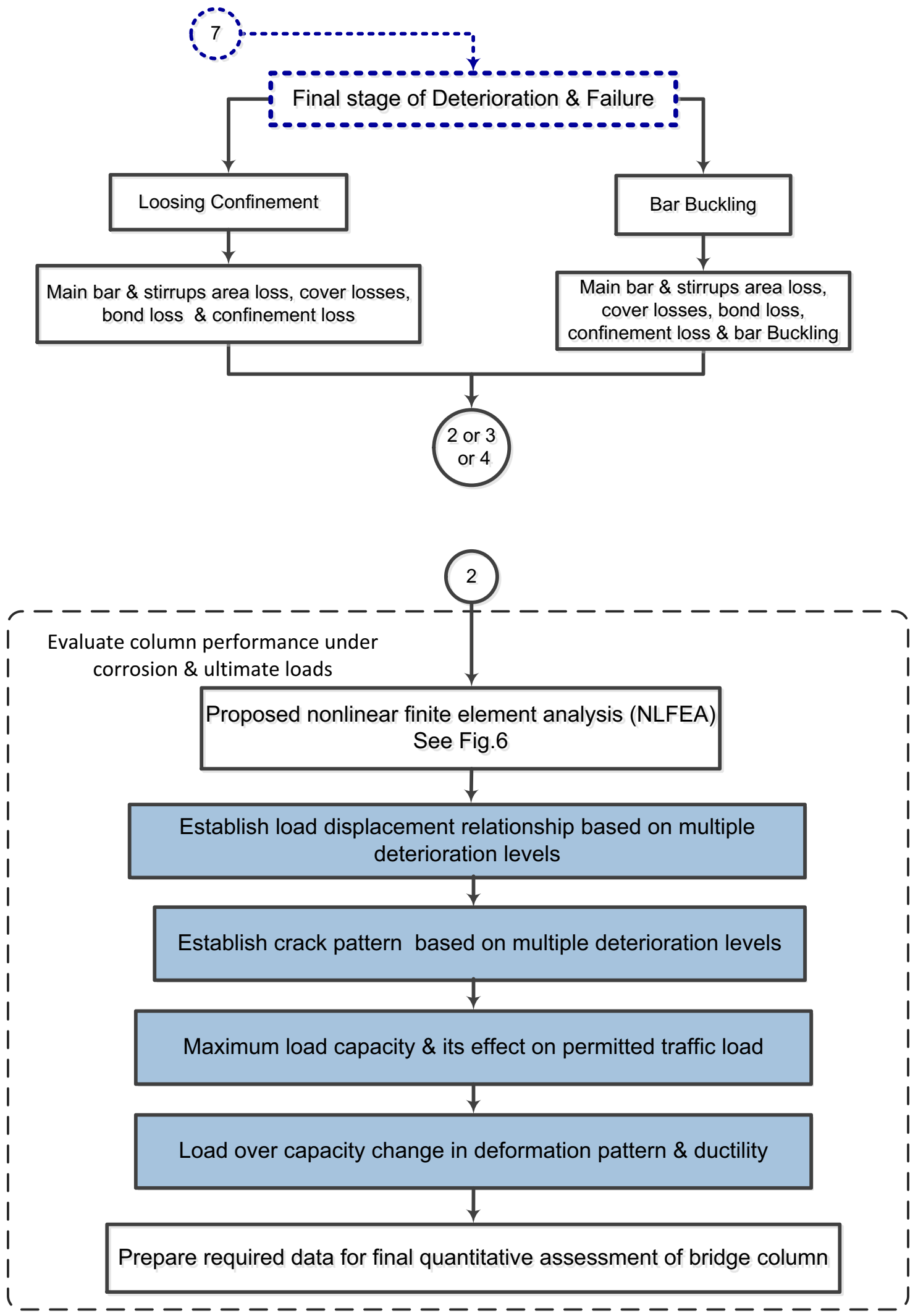

Fig. 2 (continued) 


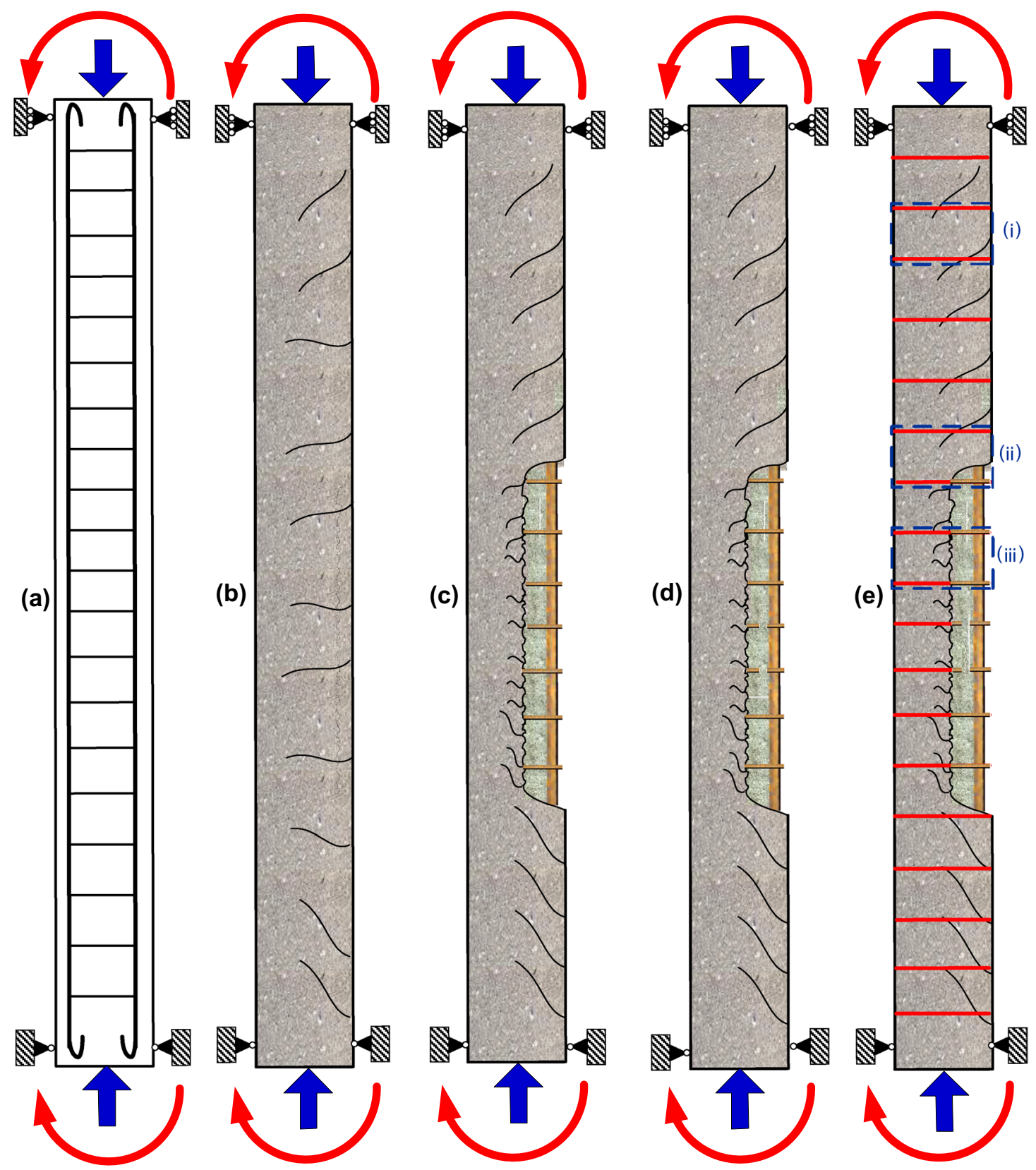

Fig. 3 Possible damage and failure modes of an RC beam-column due to combined gravity loads and corrosion; a schematic drawing; b flexural and corrosion cracks; c spalling on tension side; d stir-

element. Hence, the damage and the change in the material properties at the section level are transferred to the element level through the average changes in the instantaneous element stiffness.

\section{Loss of bond in the corrosion affected zone}

The background and the deterioration mechanisms of the rebars-to-concrete bond are discussed in detail by Mohammed (2014). It has been proven if the bond stresses outside rup failure; e beam-element discretization: (i) no corrosion damaged zone, (ii) partially corrosion-damaged zone, (iii) fully corrosion-damaged zone

the "bond failure zone" do not exceed the bond strength, then an arch mechanism is developed provided that the ends of rebars are adequately anchored. If no progressive bond failure takes place, then the possibility of high deformations due to loss of bonding action is reduced. A proposed approach to estimate the effects of the local bond loss due to corrosion on the redistribution of the stresses/forces acting on the cross sections is presented in Mohammed (2014).

The equilibrium of forces in the characteristic sections of the bond failure zone of flexural members is not directly 
satisfied (at the section level). An arch action is developed over three zones: the corrosion damaged zone and two adjacent zones that are not affected by corrosion where the equilibrium is being satisfied along the three zones (see Fig. 4a). The tensile reinforcement passing through the three zones and the distributions of the tensile and bond stresses are shown in Fig. 4a, where the excessive expansion of the corroded regionmakes additional bond stresses "migrate" from the damaged to the undamaged zones, and balancing compressive stresses are developed in terms of an arch action. In all sections where bond is active, compressive and tensile forces act as a couple to rotate the cross-sections around the neutral axis (Euler-Bernoulli beam theory). In the other cross sections where bond has failed, the internal forces acting on the sections satisfy equilibrium only in the RC structural element across the three zones (i.e., "bond failure zone" and the two neighboring "active bond zones"). Since the tension and compression forces acting on
Fig. 4 Formation and migration of bond stress "wave" throughout formation and progression of local bond failure due to corrosion

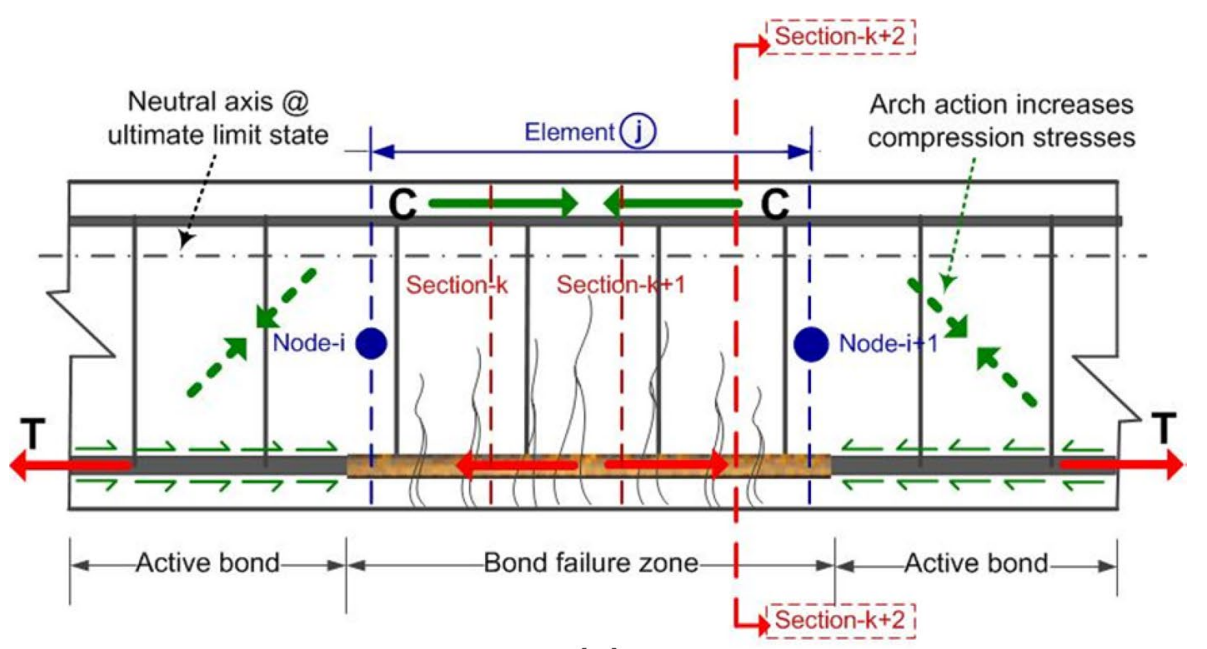

(a)

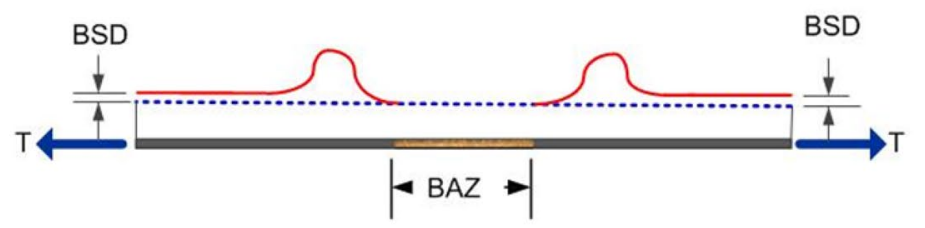

(b-i)

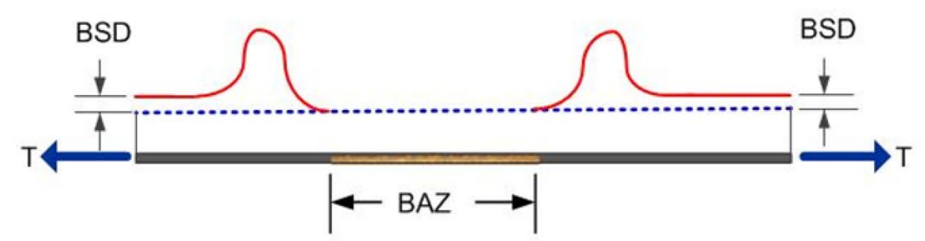

(b-ii)

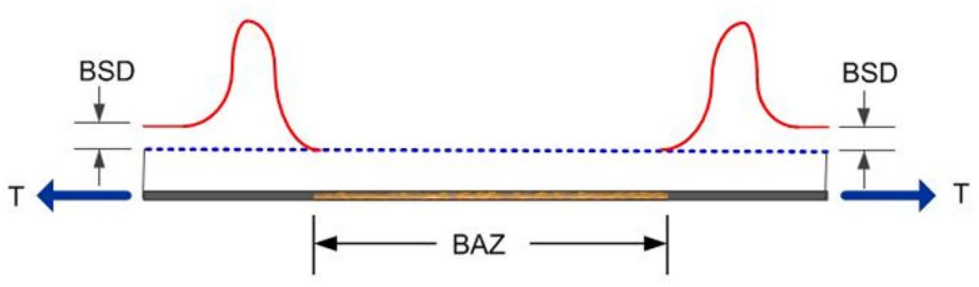

(b-iii) 
the section are not balancing each other across the section itself in the "bond-failure" zone, then two additional inclined compressive forces develop in the two side zones forming an arch, which is self-supported by the tensile force in the steel. As corrosion begins and propagates, the loss of bond is also extended along the reinforcement. While the bond loss region is expanding, bond stresses increase at the two ends of the bond failure zone, forming a high-stress transition zone where the stress redistribution takes place. Figure $4 \mathrm{~b}$ (1) through (3) shows the migration of high bond stress waves when the corrosion-induced bond loss zone expands longitudinally, where: (1) BAZ is the length of the bond affected zone of the rebar; and (2) BSD is the constant bond stress after stress re-distribution takes place. With a very high level loading case, where the load exceeds the service load but is still less than the ultimate load, further propagation and migration of the bond loss zone beyond that developed due to corrosion would likely take place. The additional bond stress due to the high increase of external loads would increase the peak stress of the "bond stress waves" at the transition regions, which could result in a progressive loss of bond leading to sudden failure.

With a significant sectional loss in tensile reinforcement, and if the tensile stresses in the affected steel are relatively high (beyond yield but still under the ultimate stresses), high local axial deformations in the tensile reinforcement are expected. This would result in widening of the flexural cracks, accelerating the local damage and concrete spalling. Furthermore, the formation of an arch action would increase the compressive stress in the "bond-failure" zone. When the structural member is subjected to axial compression in addition to bending moment (in beam-columns), the tensile stresses in the tensile steel could be significantly reduced. Hence, the stress redistribution mechanisms could not be developed, and the effects of losing the bond in the corrosion affected zone could marginally affect the lateral deformations. In the present study, the focus is on beam-columns of slab-on-girder bridges that are subjected to axial load and moment as a result of the load eccentricity. For the proposed NLFEA, the equilibrium is satisfied at the sectional and the element levels taking into account the redistribution of the stresses due to the formation of the arching action, checking whether the bond stress level exceeds the bond strength in non-corroded zones (active bond zone as shown in Fig. 4a).

\section{Loss of stirrups and concrete confinement, and longitudinal rebar buckling}

At advanced corrosion stages, fracture of critical stirrups in corrosion-damaged zones is widely observed, which could result in premature buckling of the main rebars (Rodríguez et al. 1996). In flexural members, severe localized corrosion or pitting corrosion could develop in zones that are located away from critical moment or shear sections. The reduction in structural capacity due to stirrup corrosion could be specifically serious in RC columns, as they provide confinement to the core concrete in addition to their major contribution to shear resistance. This significant effect of losing stirrups due to corrosion on the axial and bending moment carrying capacities of deteriorated RC columns has been observed by Rodríguez et al. (1996) and Oyado et al. (2007). NLFEA of $\mathrm{RC}$ beam-columns is subjected to external loads and reinforcement corrosion.

The nonlinear finite element analysis approach is presented here. This section includes the background assumptions, the nonlinear approach steps, and the "displacement field tuning convergence" (DFTC) technique.

\section{Assumptions}

The NLFEA is based on the following assumptions: (1) concrete and steel are isotropic materials; (2) the "local" stiffness matrix (with its $6 \times 6$ entries related to 3 degrees of freedom for each of the two nodes in the finite element) is established from the equivalent average of the axial and the flexural rigidities calculated over all characteristic sections of that element; (3) the flexural rigidity of each section is calculated from the base sectional analysis (see Mohammed 2014); (4) all deformations (displacements, rotations, etc.) are continuous functions over the discretized continuum (i.e., the structural element) throughout all load steps; (5) Euler-Bernoulli beam theory is applicable and the effect of stress redistribution due to bond loss is added; and, (6) equilibrium should be satisfied at both the section and structural levels.

\section{Discretization}

The NLFEA is following the typical finite element discretization of linear structural members. The column is divided into a number of finite elements of constant or variable length. The number of characteristic sections is optimized depending on the length of the member, the number and length of the finite elements, and the length of the corrosion damaged zone. The location of each characteristic section is identified based on the variation of the sectional properties and the required accuracy. In Fig. 4a, element $(j)$ joins node (i) and node $(i+1)$, and it includes as an example three characteristic sections $(k),(k+1)$, and $(k+2)$. Two approaches can be followed to select the number of elements and number of sections per element: (1) if the required processing time and the size of the structure are large, then the smallest possible number of elements with a reasonable number of sections per element has to be selected; or (2) if the variation 
of stresses is very high or the change in properties due to corrosion progress is significant, then selecting a large number of elements with a minimum number of sections is the best approach. A refined analysis is also possible when the preliminary trials raise the need to capture the steep variation of the displacements or stresses in a specified zone of the structural element. Whatever discretization approach is followed, fine tuning of the convergence parameters on a case by case basis is a key for an efficient modeling, as shown in the following sections.

\section{Nonlinear finite element procedure}

In order to achieve an acceptable model performance and accurate results, the simplified NLFEA has to show the following: (1) numerical efficiency in terms of minimum use of random access memory (RAM) and minimum processing time; (2) highly controlled and systematic convergence with minimum sensitivity; and (3) minimum time and number of trials in idealizing and discretizing. The baseline for an acceptable model performance is the simplicity of its structure, the matching to available experimental results, and numerical efficiency in terms of computing time and memory use. Throughout the evolution of nonlinear finite element analysis of RC frame structures (see Mohammed et al. 2012), the nonlinear (material, geometrical or both) element stiffness was derived using analytical approaches with closed-form integration, semi-analytical approaches, or numerical integration. High-numerical sensitivity and time-consuming convergence have been experienced when closed-form nonlinear formulation has been used. At the early development of non-linear finite element models, the use of numerical integration for each section at each load step was not an option, as it requires large memory and computational time.

The NLFEA presented here employs a numerically efficient nonlinear sectional analysis (NLSA) (see Mohammed 2014 for the details of derivation and verification). In addition, the model involves the use of "displacement field tuning convergence" or DFTC. DFTC is an innovative convergence approach where the trial and errors process to verify equilibrium at the element level is controlled by correcting the displacement vector based on the correction of the maximum displacement normal to the axis of the structural element. The correction is based on proportioning the change in the displacement in successive load increment steps and correction trials. The corrections of all deformations are assumed linearly proportional to the correction of the maximum deformation. This approach was originally developed by Almansour (1988) for nonlinear analysis of plates and shells and simplified here for the application to RC frame structures. Figure 5 shows the trial deformation fields and successive corrections (corr ${ }_{i}$, $\operatorname{corr}_{i+1}, \operatorname{corr}_{i+2}, \ldots .$, corr $_{i+n}$ ), where the deformation field is corrected successively until equilibrium is satisfied, allowing very small tolerance in the tuning process.

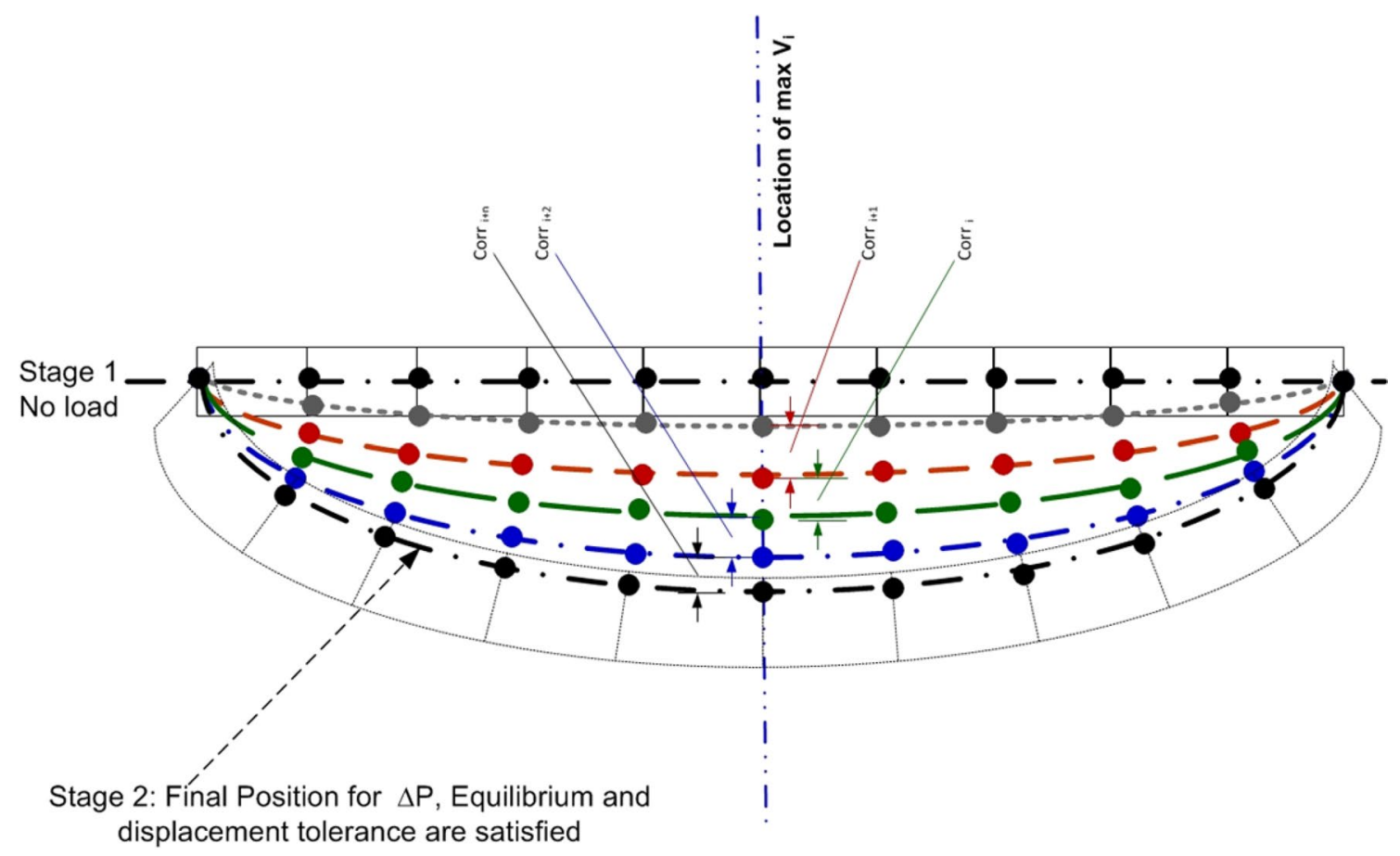

Fig. 5 Displacement field tuning convergence in the proposed nonlinear finite element analysis procedure 
For simplicity and conceptual purpose only, the figure shows that the corrected displacement curve is successively moving in one direction only, which is not always the case in the trial and error process. Figure 6 shows the NLFEA procedure assuming constant increments of the load throughout. The procedure is as follows:

1. For first applied load increment, $P_{i=1}=\Delta P$ :

(i) Find the structural stiffness, $K_{i=1}$ based on linear finite element analysis.

(ii) Solve $P_{i=1}=K_{i=1} U_{i=1}$ for the global structural deformation vector, $U_{i=1}$.

(iii) Identify the maximum vertical displacement over the deformation field (deformation vector) $V_{i=1 \text {. }}$

(iv) Find the element forces and hence the sectional forces involving bond loss effects at the element level.

(v) Perform nonlinear sectional analysis based on the results of step one to define the rigidities at the section level, and hence the stiffness for next step.

(vi) Check if the section has failed.

2. For any subsequent load increment, $P_{i+1}=P_{i}+\Delta P$

(i) Construct the nonlinear stiffness matrix based on the sectional properties of each element in the previous load step, $K_{i}$.

(ii) Solve $P_{i+1}=K_{i} U_{i+1}$ for the global structural deformation vector, $U_{i+1}$.

(iii) Identify $V_{i+1}$ and calculate the correction, Corr- ${ }_{i}$, which is found as (maximum $V_{i+1}$-maximum $\left.V_{i 1}\right)$ /maximum $V_{i}$, where maximum $V_{i}$ should be compared to the tuning variable, $\alpha$, which is introduced to control "tune" the convergence.

(iv) The modification of the deformation vector is assumed linearly proportional to the maximum displacement normal to the structural member axis, $U_{i}{ }^{\text {corr- }-i}=U_{i} *\left(1+\operatorname{Corr}_{-i}\right)$. That is, it corresponds to the maximum displacement, $V_{i}^{\text {corr }-i}$.

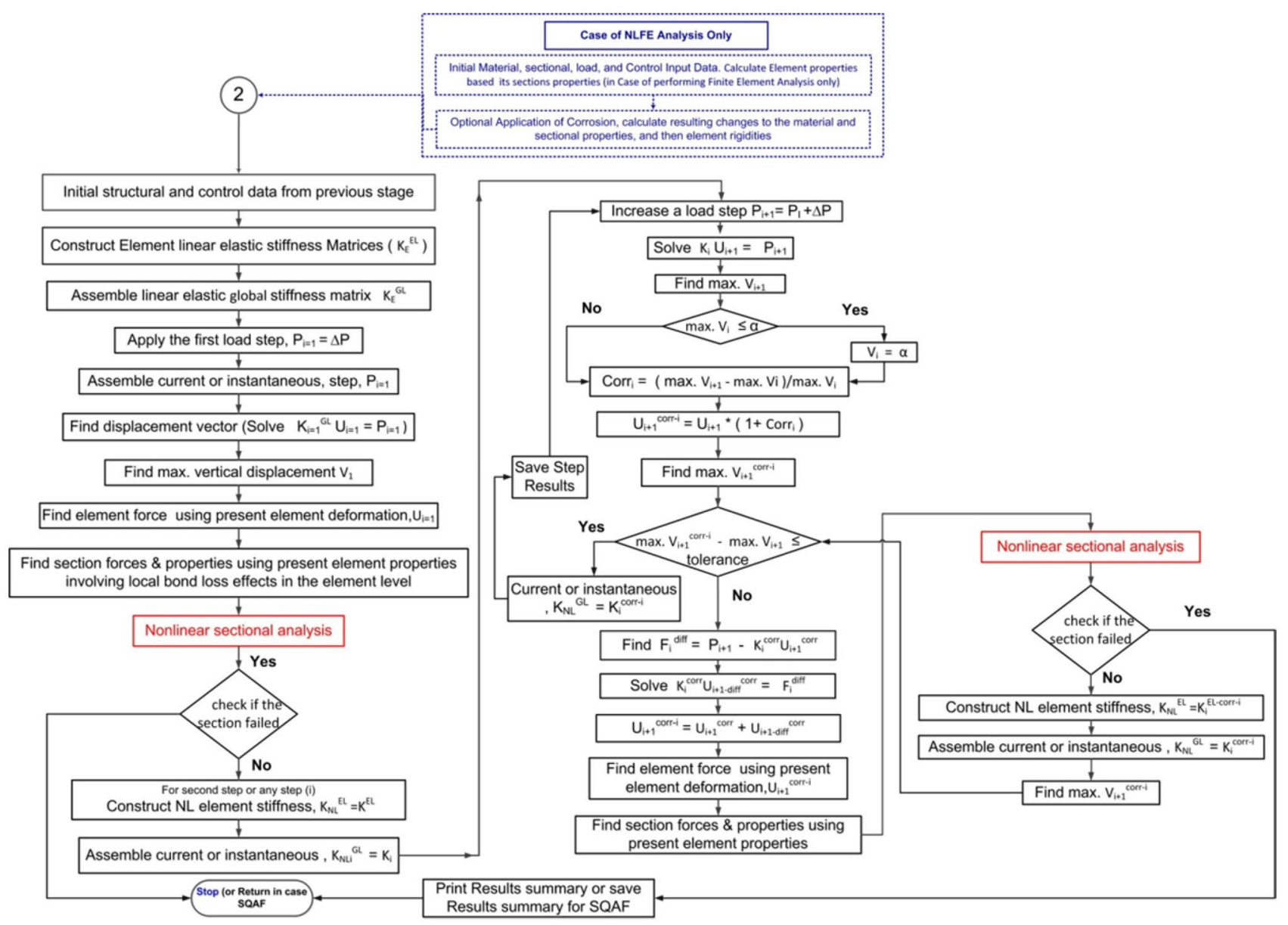

Fig. 6 Proposed nonlinear finite element analysis approach 
(v) Check the tolerance for the displacement.

(vi) If the tolerance is not satisfied, initiate a second cycle of correction based on the instantaneous difference in the force vector, or, $F_{i}$ diff $=P_{i+1}-K_{i}{ }^{\text {corr }} U_{i+1}{ }^{\text {corr }}$.

(vii) Solve, $F_{i}{ }^{\text {diff }}=K_{i}{ }^{\text {corr }} \times U_{i+1 \_ \text {diff }}{ }^{\text {corr }}$ for $U_{i+1 \_ \text {diff }}{ }^{\text {corr }}$.

(viii) Find the element using the present element deformation vector, $U_{i+1}^{\text {corr }-i}$.

(ix) Find sectional forces and properties using the present element properties.

(x) Perform nonlinear sectional analysis to find the stiffness for next step.

(xi) Check for section failure (concrete crushing in the compressive zone or tensile failure of the steel in the tensile zone).

(xii) Re-assemble the instantaneous corrected stiffness matrix and solve the finite element matrix equilibrium equation for displacement and then find the maximum displacement at this correction sub-step.

(xiii) Check the tolerance until satisfied; otherwise, establish a new correction cycle.

(xiv) If the tolerance is satisfied, save the results and increase the load.

It is important to mention that the above proposed procedure recognizes the direction of the reference displacement component (normal or parallel to the structural element axis) for the use in DFTC based on the direction of the dominant load. If the external moments due to eccentricity or bending moment due to lateral loading are controlling the structural behavior (where the flexural stresses are significantly higher than the axial stresses, such as in beams), then the tuning is based on the maximum deformation normal to the structural member. If the external axial load generates sectional stresses that control the behavior (column action), then the tuning is based on the maximum deformation in the direction of the structural member.

\section{Case studies}

Five case studies are presented in the following section, four of which are to verify the performance and accuracy of the proposed NLFEA against experimental results in the lack of field data collected from existing bridges; the fifth is to show the capability of the model to analyze a beam-column under different loading cases. Two of the four verification case studies correspond to structural elements subjected to only external "mechanical" loads; however, in order to investigate the effect of the corrosion damage in critical flexural zones, a corrosion-damaged zone is added to each of the two case studies (as shown below). The other two verification case studies correspond to structural elements that are subjected to combined external loads and reinforcement corrosion.

\section{Verification of the proposed model for the case of non-damaged structure}

In the first case study (case study I), a simply supported beam subjected to four-point loading is loaded up to failure as shown in Fig. 7a (Rasheed and Dinno 1994a). The beam is modeled to verify the accuracy and numerical stability of the proposed NLFEA. The beam is $3.0 \mathrm{~m}$ long and has a cross section of $152.4 \mathrm{~mm}$ by $280.0 \mathrm{~mm}$, with $29.2 \mathrm{~mm}$ and $34 \mathrm{~mm}$ as bottom and top concrete covers, respectively. The beam is doubly reinforced at the top and bottom faces by three carbon steel rebars of 14-mm diameter on each side, as shown in the cross section of Fig. 7a. The compressive strength of the concrete is $f^{\prime}{ }_{\mathrm{c}}=41 \mathrm{MPa}$. For the steel, the modified tri-linear expressions of the stress-strain relationship of black steel adopted from Yalcin and Saatcioglu (2000) are used. The beam is modeled for verification purposes, by comparing the finite element results to the original experimental results in terms of the moment versus mid-span curvature for the case when the beam has no corrosion damage. To extend the analysis to include corrosion damage, reinforcement corrosion is assumed to occur along the middle third of the beam span at the tension zone. Figure 7 a shows the location and the expected damage due to corrosion.

Figure $7 \mathrm{~b}$ shows that the moment versus mid-span curvature relationship of the proposed NLFEA for the case of no corrosion damage is conservatively close to the experimental results of Espion and Halleux (1988). The figure also shows the drop in moment strength and the change in the curvature capacity as a result of tensile reinforcement corrosion. The corrosion affects the beam by stiffness reduction and stress redistribution. The reduction of the steel reinforcement cross-sectional area and steel ductility is based on a steel mass loss of 30\%. Concrete spalling over the corrosion damaged area (see Fig. 7a), with full bond loss along the tension reinforcement of the corrosion-affected zone, is assumed. The failure of stirrups would only affect the shear capacity of the affected area [no effect on the concrete confinement, (Espion and Halleux 1988)]. It is observed from Fig. $7 b$ that the structural ductility of the beam measured on the basis of curvature (ductility index equal to ultimate curvature divided by yield curvature) is slightly increased. However, the beam ultimate moment strength is reduced, and the yield curvature is increased, which reflects a more softened behavior of the beam.

In case study II, a simply supported beam subjected to uniform distributed load up to failure, as shown in Fig. 8a (Rasheed and Dinno 1994b), is modeled. The beam is $2.235 \mathrm{~m}$ long and has a cross section of $152.4 \mathrm{~mm}$ by 

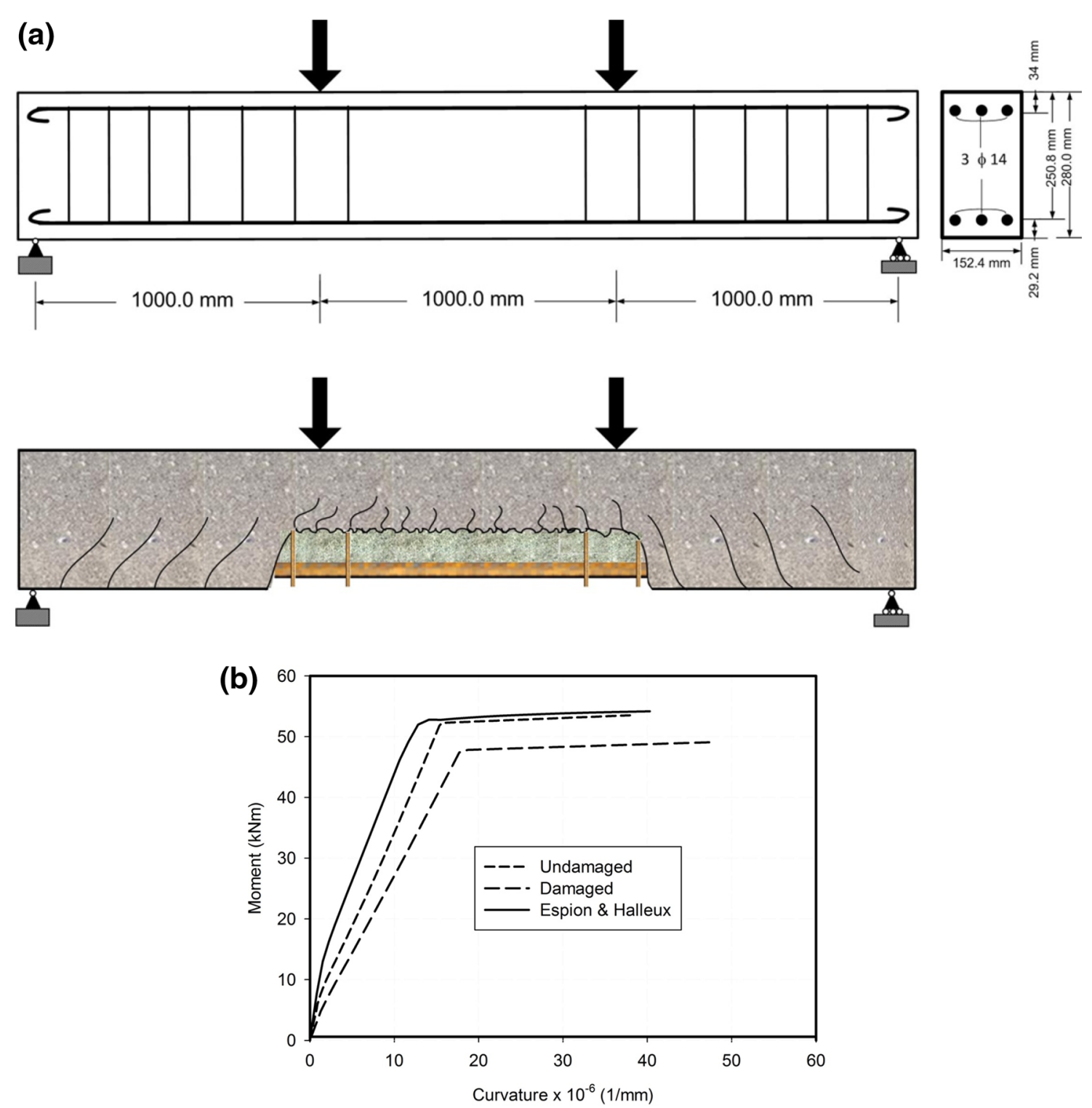

Fig. 7 a Case study I: beam under fourpoint loading (Rasheed and Dinno 1994a) subjected to corrosion over the middle one-third of the span. b Case study I: Load versus mid-span curvature for an undamaged and a damaged beam (Espion and Halleux 1988)

$304.8 \mathrm{~mm}$ with $51.3 \mathrm{~mm}$ cover. The beam is reinforced in the lower face (tension zone) by three-carbon steel rebars of $20 \mathrm{~mm}$ diameter. The compressive strength of the concrete is $f^{\prime}=34 \mathrm{MPa}$, and the stress-strain behavior of the steel is modeled as in case study I. This beam is also modeled for verification purposes, by comparing the finite element results of the load versus mid-span deflection to both the original experimental results and Rasheed and Dinno's closed-form finite element analysis (FEA) (Rasheed and Dinno 1994b). A second round of the beam analysis assumes reinforcement corrosion to affect the tension zone of the middle-third of the beam's span. Figure 8a shows the location and the expected damage due to corrosion assuming a steel mass loss of $40 \%$.
Figure $8 \mathrm{~b}$ shows that the load versus mid-span displacement relationship of the proposed NLFEA and that of (Rasheed and Dinno 1994b) are very close to the test results (De Cossio and Siess 1960). The figure also shows that using a small number of elements with more than one characteristic section per element gives similar results to the case when using a relatively large number of elements with one characteristic section per element. Reinforcement corrosion affects the beam in a similar manner as in case study I, where the reduction of the steel reinforcement section and ductility and concrete spalling would occur in an extreme corrosion state (Fig. 8c). Similar to the previous case study, the failure of stirrups would only affect the shear capacity of the affected area (De Cossio and Siess 1960). 


\section{(a)}
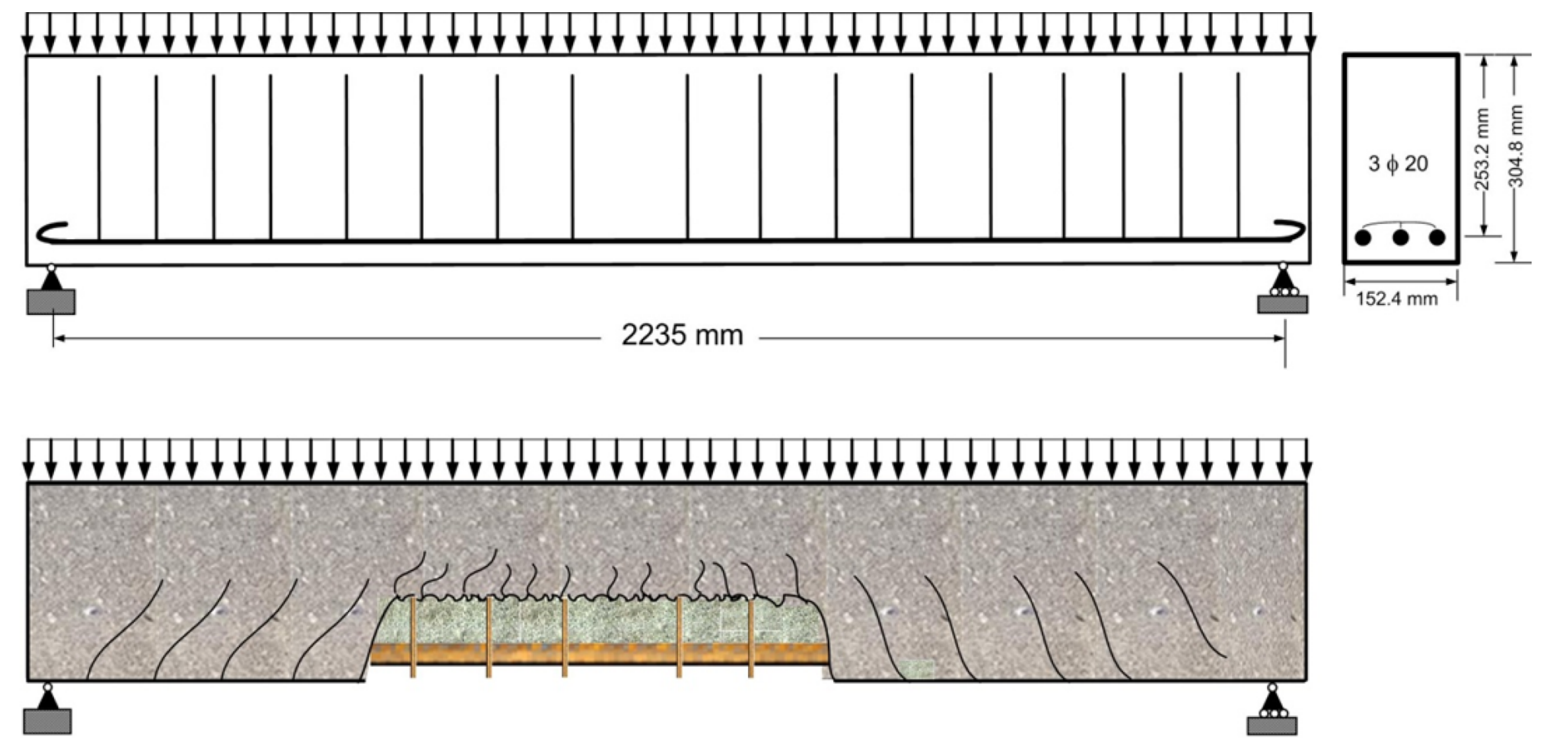

(b)

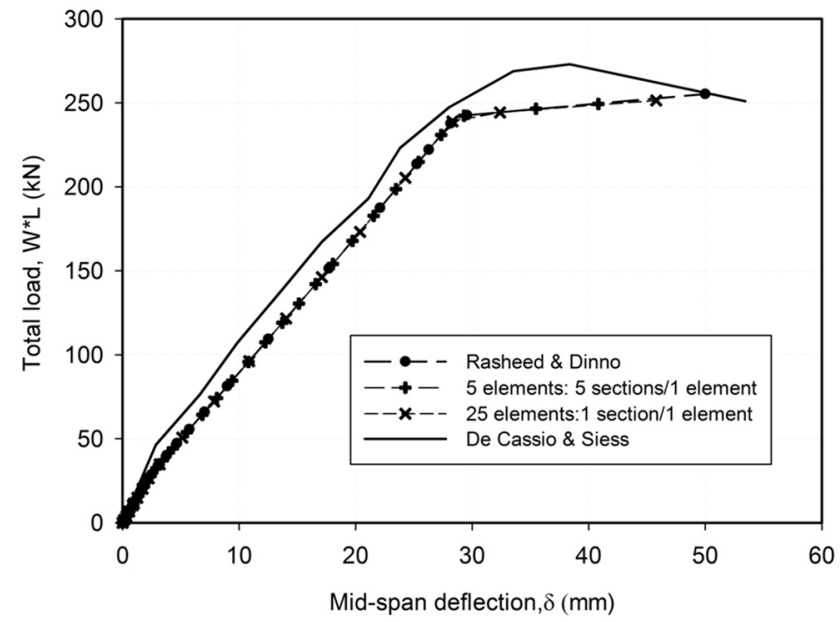

Fig. 8 a Case study II: simply supported beam under uniformly distributed load (De Cossio and Siess 1960 and Rasheed and Dinno 1994b) subjected to corrosion over the middle one-third of the span. b Case study II: Load versus mid-span deflection of a simply supported beam subjected to uniform distributed load (UDL) (De Cossio

In both case studies, the NLFEA proposed herein gives very good results that match with acceptable accuracy the experimental test results in the case of non-damaged beams. The approach is numerically stable and insensitive over a wide range of number of elements and size of load increments. The tuning parameter, $\alpha$, of the displacement field tuning convergence (DFTC) can be calibrated with only a few trials in both case studies, and the convergence of the model becomes systematic in almost all the studied cases. (c)

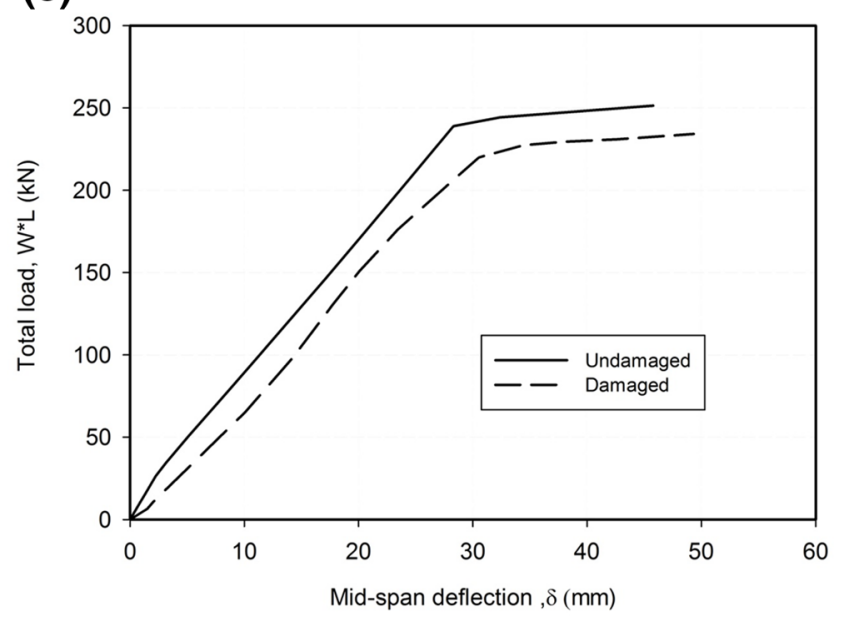

and Siess 1960; Rasheed and Dinno 1994b). c Case study II: Load versus mid-span deflection for the beam when subjected to UDL only (undamaged) or when subjected to reinforcement corrosion at midspan as well (damaged)

\section{Verification of the proposed model for the case of combined external loads and reinforcement corrosion}

In case studies III and IV, comparisons of the proposed NLFEA results with the results of analytical and experimental studies are presented. In case study III, the NLFEA is compared to a nonlinear two-dimensional FEM proposed by Coronelli and Gambarova (2004) and to the background test performed by Rodríguez et al. (1996). In Coronelli and 
Gambarova's model, the concrete was modeled using a fournode plane-stress element with thickness equal to the section width, while the steel bars were represented by two-node truss elements; a bond-link element exhibiting a relative slip between the two materials coupled the concrete elements to the corresponding bar elements. The model takes into account the effects of corrosion on the behavior of steel and concrete through: (1) the reduction of the steel rebars crosssectional area; (2) changes of the constitutive stress-strain relationships of steel and concrete in the corrosion affected zone; (3) changes of the material interface properties; and (4) loss of the concrete cover due to spalling.

Coronelli and Gambarova (2004) compared their model results with Rodríguez et al. (1996)'s experimental results of a simply supported beam subjected to four-point loading and reinforcement corrosion. Rodríguez et al. (1996) tested several beams with different properties; however, one of those beams (11.6, as named in Rodríguez et al. (1996) study) is selected for the present case study. The load versus mid-span deflection relationships of the proposed NLFEA compared to both Coronelli and Gambarova (2004)'s modeling results and the original Rodríguez et al. (1996)'s test results are shown in Fig. 9. A close agreement is observed between the proposed model and the two sets of results, where the proposed model shows slightly conservative results.

In case study IV, the results of the proposed NLFEA are compared to Yingang et al. (2007)'s test results. Nineteen RC simply supported beams were loaded under two-point loading up to failure; they were subjected to a process of electrochemically accelerated corrosion. The specimens have dimensions of $150 \times 200 \times 2100 \mathrm{~mm}$ and a span of $1800 \mathrm{~mm}$. The beams are reinforced with tension reinforcement ratio of $0.87,1.6,3.2$, and $6.2 \%$ in four groups (very under-reinforced, under-reinforced, balanced, and over

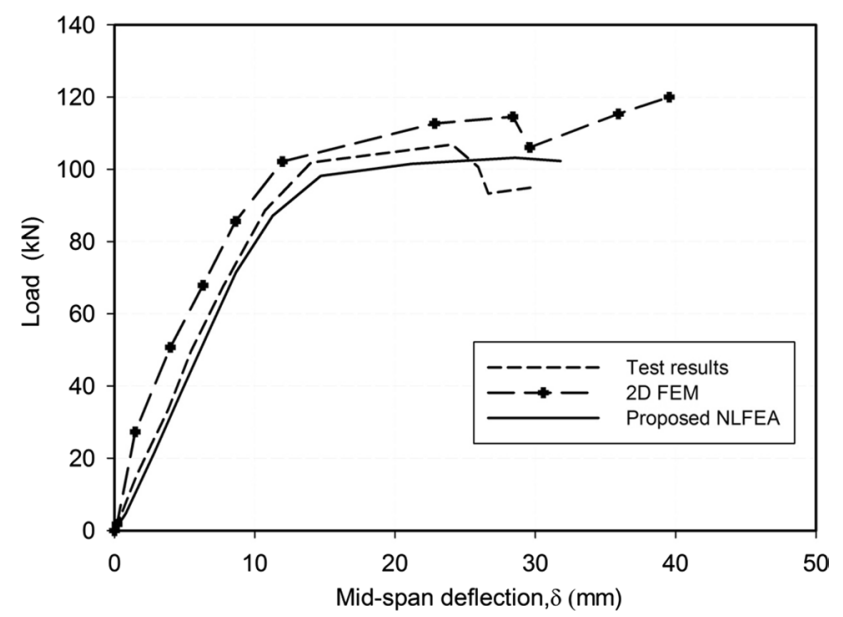

Fig. 9 Case study III: comparison of the proposed NLFEA results to experimental and numerical results of Rodríguez et al. (1996) and Coronelli and Gambarova (2004), respectively reinforced). The beams are reinforced with $8 \mathrm{~mm}$ ties at $150 \mathrm{~mm}$ spacing, either with 0.56 or $0.87 \%$ transverse reinforcement ratios. The nominal concrete cover to the longitudinal bars was $20 \mathrm{~mm}$. In this case study, an over reinforced specimen (T322) was selected for the comparison. For the selected specimen, tension bars were intentionally corroded with direct current impressed on the individual sets of bars. For the selected specimen, the current intensity was $0.9 \mathrm{~mA} /$ $\mathrm{cm}^{2}$ applied for 60 days.

Figure 10 shows the NLFEA results for the load versus mid-span deflection relationships compared to the test results of undamaged and corrosion-damaged beams. The figure shows that the NLFEA slightly underestimates the ultimate load. The results show that the NLFEA conservatively predicts a softer behavior, reflecting a lower stiffness than that of the tested specimen. This can be explained by the conservative simulation of the nonlinear material properties of both the concrete and the steel, where: (1) the concrete contribution to the sectional stiffness using the secant modulus gives underestimation of the stiffness; and (2) the tri-linear stress strain relationship of the steel could result in softer behavior in the test range of stresses.

In both case studies III and IV, convergence is satisfied in all cases of damaged and undamaged beams. The capability of the NLFEA to capture the ultimate load and deformation and its numerical stability and fast convergence enhance the confidence for its use in more complex applications.

\section{NLFEA to predict structural performance of a beam-column subjected to combined eccentric load and reinforcement corrosion}

In case study V, the NLFEA is applied to predict the structural behavior of a slab-on-girder bridge column subjected

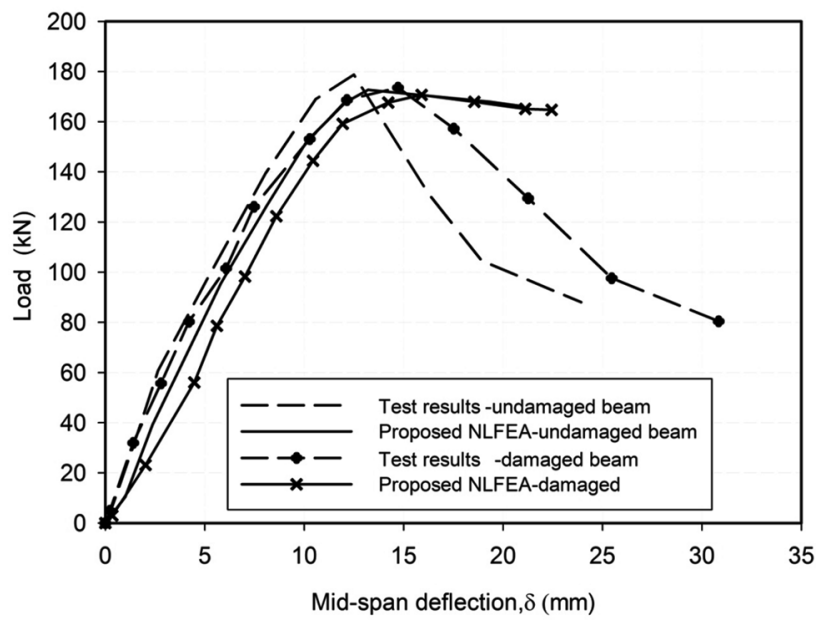

Fig. 10 Case study IV: comparison of the proposed NLFEA results to experimental results from Yingang et al. (2007) 
Fig. 11 a Case study V: bridge column of slab-on-girder bridge subjected to local corrosion. b (i) Case study V: sample of slab-on-girder bridge columns with partial corrosion damage (Gardiner Parkway-Expressway, Toronto, Canada). (ii) Case study V:(a) most affected corrosion zone on a slab-on-girder bridge column; (b) column reinforcement and location of mid-height section; (c) column cross-section details. c Case study V: possible damage of RC beam-column subjected to combined external loads and corrosion: (a) flexural and corrosion cracks; ( b) initial spalling; (c) one stirrup failure; (d) spalling on all sides; (e) two stirrups failure; (f) loss of confinement and possible buckling. $\mathbf{d}$ Case study V: FE discretization of the column and lateral displacement of un-corroded (UC) and corroded (CO) column, both with $e=5 \mathrm{H}$, for (a) below yield load $(M=3000 \mathrm{kN} \cdot \mathrm{m})$; (b) after yield and below ultimate $(M=6000 \mathrm{kN} \cdot \mathrm{m})$; and, (c) at ultimate load $\left(M_{\mathrm{UC}}=8200 \mathrm{kN} \cdot \mathrm{m}\right.$ and $\left.M_{\mathrm{CO}}=6750 \mathrm{kN} \cdot \mathrm{m}\right)$. e Case study V: $\mathrm{M}-\Delta_{\text {lateral }}$ at the midheight section of the column where the corrosion load is applied, for $e=5 \mathrm{H}$ and for different corrosion cases

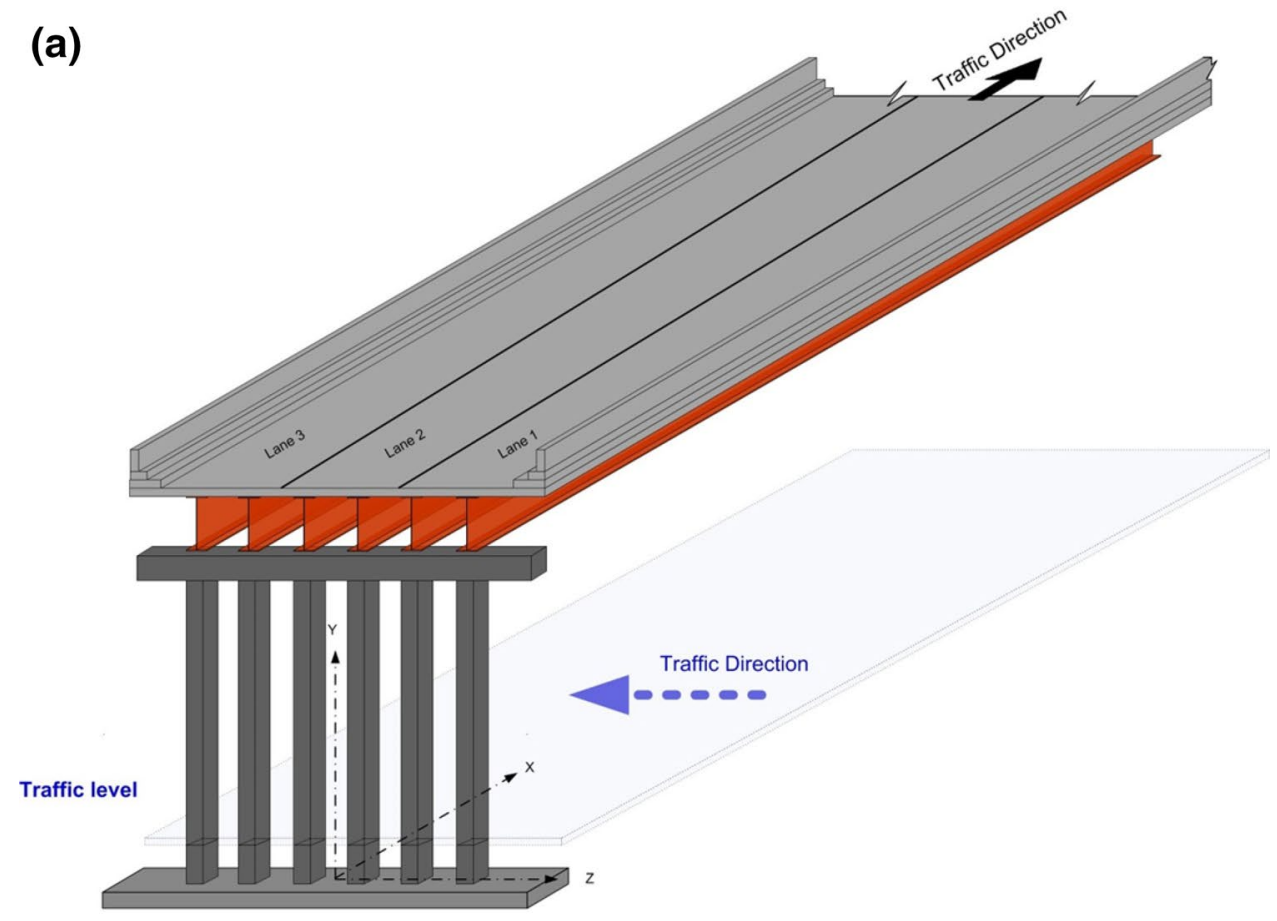

(b)

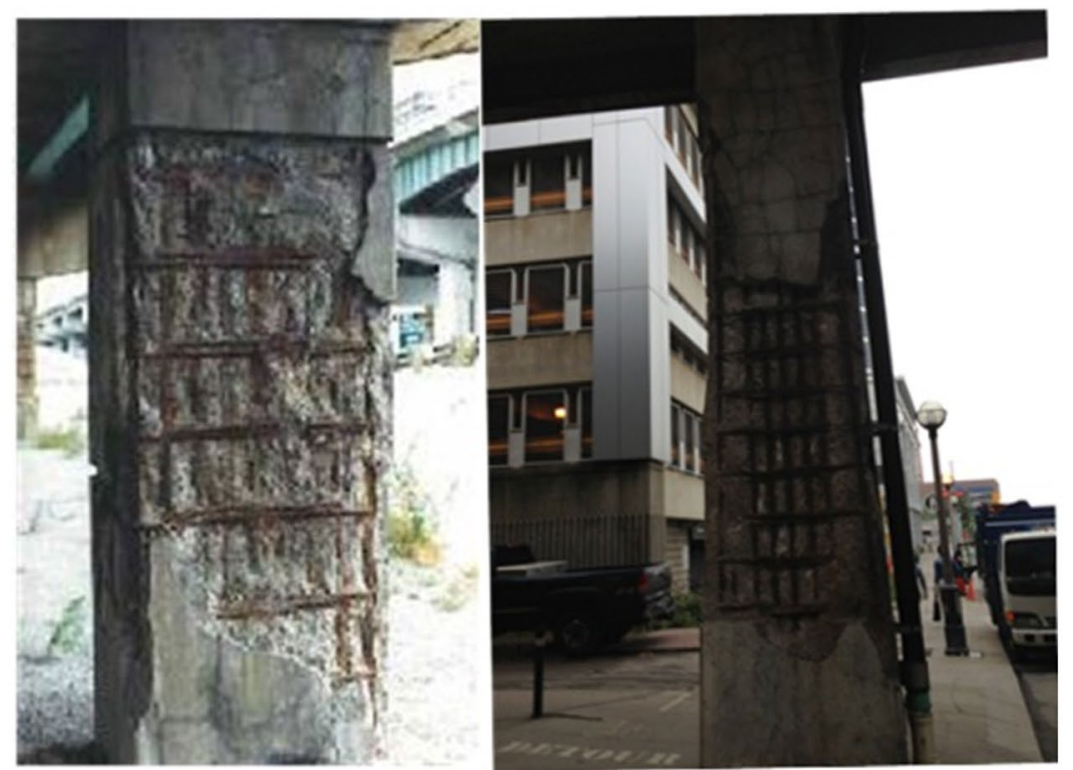

to axial load with variable eccentricity combined with reinforcement corrosion. Figure 11a shows a typical slab-ongirder pier formed from several columns. The columns are usually supported by a rigid strip foundation with or without piles depending on the soil conditions, and the columns are usually connected at the top by a "cap" beam normal to the traffic direction. This cap beam provides continuity in the direction normal to the traffic and a base for the bridge superstructure, as shown in the figure. A pin support is usually assumed in the direction of the traffic. Slab-ongirder bridge columns are typically designed to support low eccentricity; however, in this case study, high eccentricity is assumed for an aged bridge structure to investigate extreme loading conditions that could result from a progressive damage in the superstructure and/or the substructure.

Figure 11b (i) shows typical critical corrosion zones on slab-on-girder bridge columns. Figure 11 b (ii) (a) shows a possible worst scenario for the location of a corrosion damaged zone in an intermediate bridge column of a highway overpass. Such corrosion damage can be due to splashing of de-icing water from two-direction traffic. In this case study, it is assumed that the corrosion would affect the middle third 
Fig. 11 (continued)

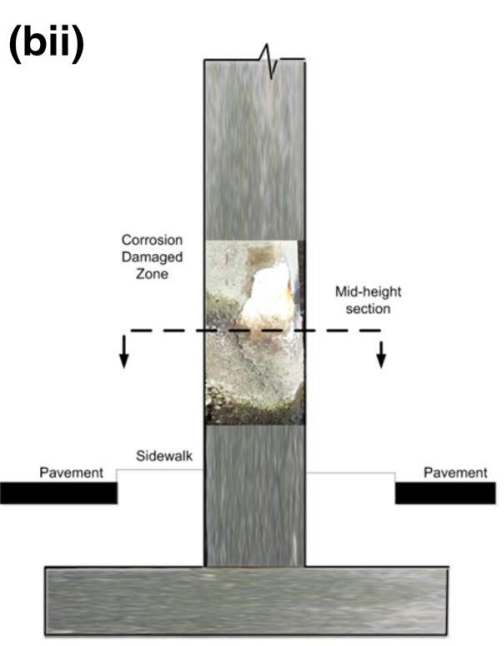

(a)

(c)
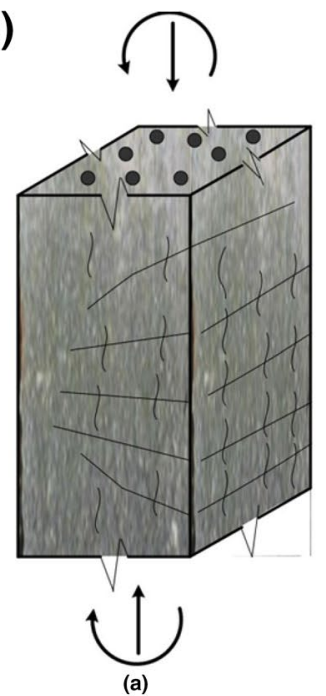

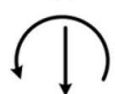

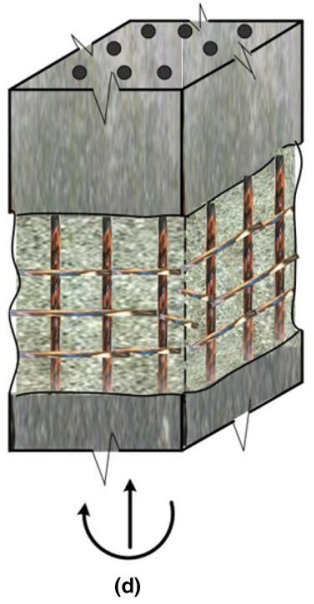

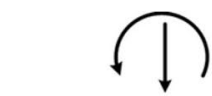

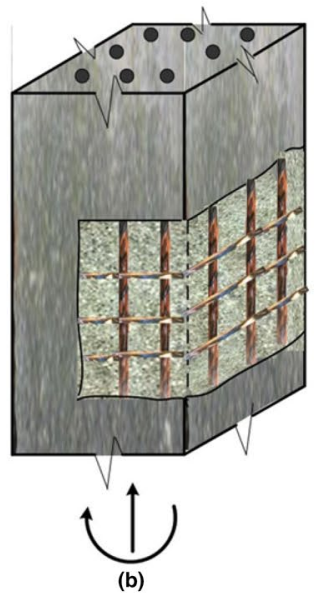

D

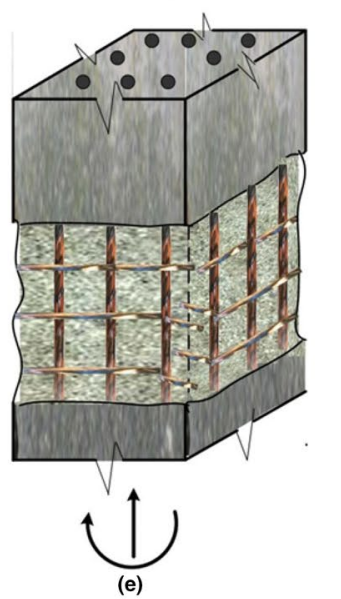

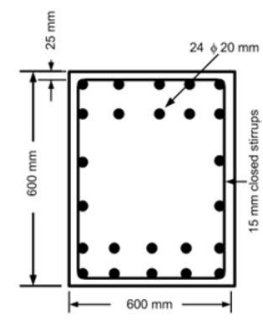

(c)

(b)

D

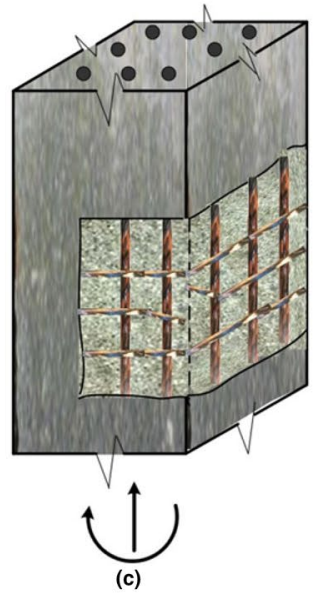

$\downarrow$

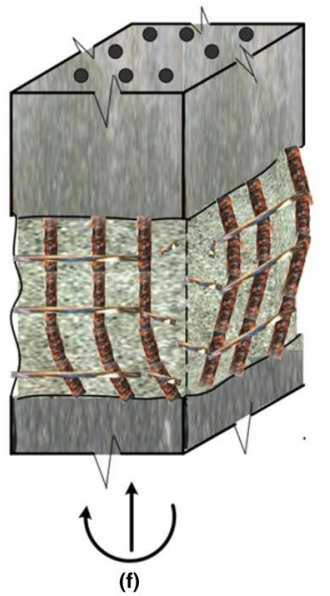


Fig. 11 (continued)

of the 6.0-m height column. Figure 11b (ii) (b) shows the typical details of the longitudinal and lateral reinforcement of such column, while Fig. 11b (ii) (c) shows the column cross section details, where the larger amount of longitudinal reinforcement is provided in the traffic direction.

The bridge column under consideration is under high external axial load and eccentricity. Hence, concrete confinement is of major interest in evaluating the structural behavior and residual capacity of the column. Several possible corrosion damage states can be assumed similar to those states of damage observed in Canadian bridges in service, as shown in Fig. 11c. The figure shows six possible damage states that are directly related to different structural performance states: (a) Corrosion-induced cracks combined with flexural and lateral expansion cracks, where corrosion growth on the longitudinal and lateral reinforcement results in losses of the steel cross-sectional area; (b) concrete cover spalling off one side, partial loss of cover from two orthogonal sides, and high reduction of steel area and ductility; (c) a possible rupture of one lateral reinforcement tie/stirrup after experiencing all the damages in (b) above; (d) spalling of concrete cover all-around the column together with steel (d)

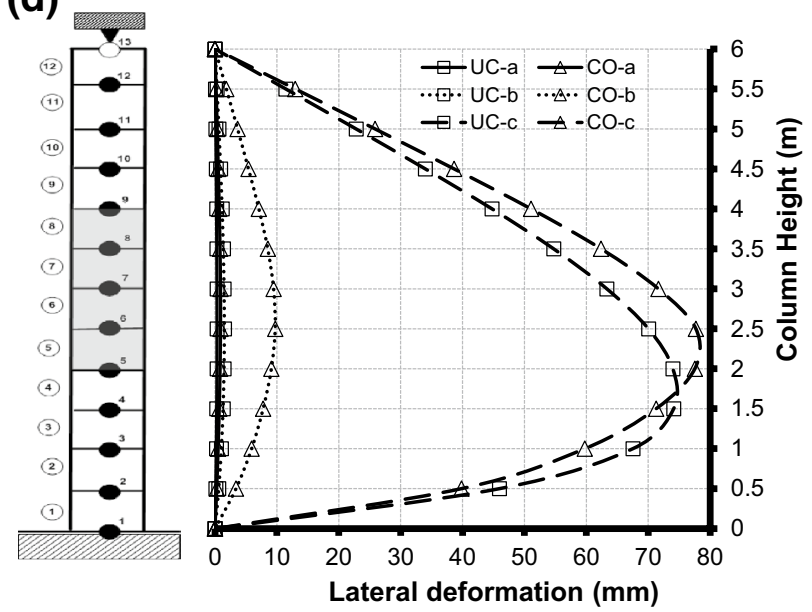

(e)

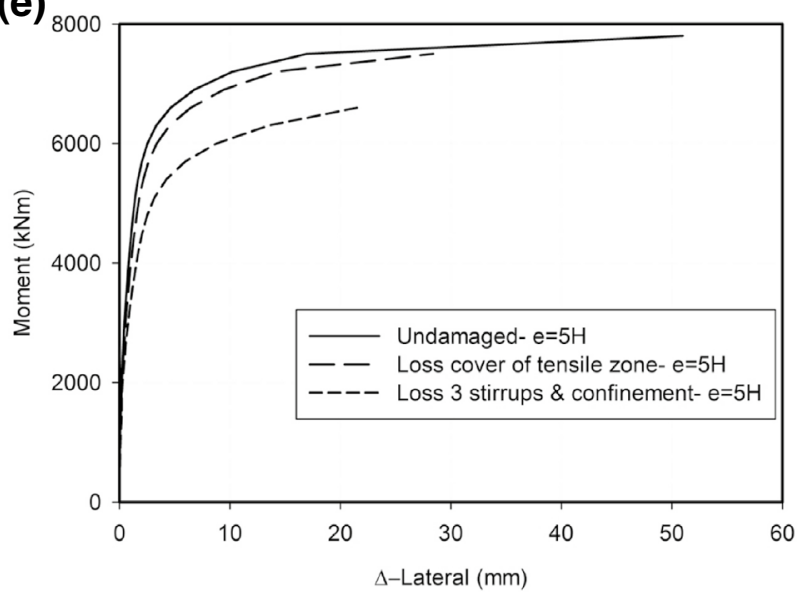

losses of longitudinal and lateral reinforcement and rupture of one stirrup/tie; (e) spalling of concrete cover all-around the column together with steel losses of longitudinal and lateral reinforcement and rupture of two stirrups/ties; and, (f) spalling of concrete cover all-around the column together with significant steel losses of longitudinal and lateral reinforcement, rupture of three stirrups/ties together with local loss of confinement and longitudinal bar buckling.

Figure 11d shows the finite element idealized column with 12 elements, 13 nodes, and fixed-pin support conditions at the ends. The column is subjected to load increments up to ultimate capacity. An eccentricity e ranging from zero to $5 \mathrm{H}$ is assumed in all the load steps in the present case study, where $\mathrm{H}$ is the depth of the column cross section in the traffic direction. This range of eccentricity is assumed here to cover all possible extreme loading cases resulting from progressive damage of different parts of aging bridges. It also enables the demonstration of the capability of the proposed NLFEA in modeling a wide range of structural behavioral cases, covering pure axial compression, pure flexure, and any combination of axial compression and bending moment in beam-columns. Figure 11d also shows the distribution of lateral displacement 
over the column height when high eccentricity is assumed. The figure shows the lateral displacement for the case of no corrosion or undamaged column (UC) versus the case of corrosion damaged column (CO). Extreme corrosion deterioration is assumed in the analysis, which involves spalling of the concrete cover all-around the column together with massive steel losses of longitudinal and lateral reinforcement (assuming a steel mass loss of $30 \%$, which is equivalent to 10 years of corrosion with a current density of $1 \mu \mathrm{A} / \mathrm{cm}^{2}$ ), rupture of three stirrups, and loss of confinement prior to the possible occurrence of buckling of longitudinal reinforcement. For both the undamaged column (UC) and corrosion-damaged column (CO), Fig. 11d shows the lateral displacement over the height for three load cases: (a) below yield, at a moment equal to $3000 \mathrm{kN} \cdot \mathrm{m}$, with an axial load of $833 \mathrm{kN}$; (b) after yield and below ultimate, at a moment equal to $6000 \mathrm{kN} \cdot \mathrm{m}$, with an axial load of $1667 \mathrm{kN}$; and (c) at ultimate, for UC: a moment equal to $8200 \mathrm{kN} \cdot \mathrm{m}$, with an axial load of $2280 \mathrm{kN}$, and for CO: a moment equal to $6750 \mathrm{kN} \cdot \mathrm{m}$, with an axial load of $1875 \mathrm{kN}$. The figure shows the overall increase in lateral displacement for the case of the corrosion-damaged column versus the non-corroded column, specifically at ultimate loads. It is also observed that the region of maximum displacement is moved upward to the zone affected by corrosion (see the two curves UC-c versus $\mathrm{CO}-\mathrm{c}$ ). This may lead to a general conclusion that critical sections identified at the design stage could not necessarily remain critical sections for the evaluation of aged structures, even if no concentrated corrosion is assumed. Hence, a preliminary parametric study is essential to identify the critical "evaluation" sections.

Figure 11e shows (for the case of high eccentricity, i.e., $e=5 \mathrm{H}$ ) the effect of two corrosion-induced damage states on the moment versus lateral displacement relationship. The figure shows an intermediate corrosion damage case (loss of cover on the tensile face) and an extreme corrosion damage case (loss of the three stirrups and confinement). The large reduction in moment and lateral deformation capacities as corrosion damage is accumulated is evident in the results presented in Fig. 11e.

This case study shows the general capabilities of the proposed NLFEA in estimating the ultimate capacity of the strengths and deformations of beams, columns, and beamcolumns. The model can be easily integrated with (1) a model for nonlinear dynamic analysis of the effects of traffic on the bridge structure due to corrosion-damaged bridge columns (see Mohammed et al. 2014), and (2) a model for seismic analysis of corrosion-damaged bridge columns.

\section{Conclusions}

In this paper, a numerically efficient nonlinear finite element analysis (NLFEA) is proposed as part of a semiquantitative assessment approach to evaluate the structural performance and residual capacities of beam-columns subjected to combined external loads and reinforcement corrosion. The model is capable of simulating the nonlinear structural behavior of corrosion-damaged aged beamcolumns with any possible gravity loading. The NLFEA uses nonlinear sectional analysis, enhanced inspection, and material testing to estimate the column sectional rigidities. The elements and structure stiffness are estimated by a trial and error, ensuring equilibrium at the sectional, element, and structural levels at each load step. The results of the case studies lead to a general conclusion that critical sections identified at the design stage do not necessarily remain critical sections for the evaluation of an aged structure.

The efficiency and accuracy of the proposed NLFEA is verified through four case studies, which are compared to experimental and numerical results from previous studies on both undamaged and corrosion-damaged beam columns. The procedure is comprehensively applied on a typical slabon-girder bridge column, giving trends of structural behavior and results as expected. The procedure proves to be numerically efficient and insensitive to values of the controlling parameters of the nonlinear analysis. The NLFEA can be used as part of a nonlinear static or dynamic analysis of damaged bridge columns or framed structures, and it can be integrated with a semi-quantitative assessment approach.

Open Access This article is distributed under the terms of the Creative Commons Attribution 4.0 International License (http://creativeco mmons.org/licenses/by/4.0/), which permits unrestricted use, distribution, and reproduction in any medium, provided you give appropriate credit to the original author(s) and the source, provide a link to the Creative Commons license, and indicate if changes were made.

\section{References}

Almansour H (1988) The structural analysis of partially buttressed reservoir walls using finite element method. M.Sc. Thesis. University of Basrah, Basrah, Iraq

American Association of State Highway and Transportation Officials (2000) Manual for condition evaluation of bridges, 1994. American Association of State Highway and Transportation Officials, Washington

American Association of State Highway and Transportation Officials (2007) AASHTO LRFD bridge design specifications SI units, 4th edn. American Association of State Highway and Transportation Officials, Washington 
Brown G, Grave S, Boorman G (2010) Bridge inspection standards-a review of international practice to benchmark bridge inspection standards for KiwiRail Network's bridges; Beca and KiwiRail

Canadian Standards Association (2006) Canadian Highway Bridge Design Code, CAN/CSA-S6-06, A. Canadian Standards Association, Mississauga

Coronelli D, Gambarova P (2004) Structural assessment of corroded reinforced concrete beams: modeling guidelines. J Struct Eng 130(8):1214-1224

De Cossio R, Siess P (1960) Behavior and strength in shear of beams and frames without web reinforcement. J Am Concr Inst 56:695-735

Espion B, Halleux P (1988) Moment curvature relationship of reinforced concrete sections under combined bending and normal force. Mater Struct 21(5):341-351

Lounis Z, Vanier DJ, Daigle L, Sadiq R, Almansour H (2010) Framework for assessment of state, performance and management of core public infrastructure, NRC Canada, project 5332-final report

Ministry of Transportation (2008) Ontario structure inspection manual (OSIM), policy, planning and standards division engineering standards branch bridge office. Ministry of Transportation, Toronto

Mohammed A (2014) Semi-quantitative assessment framework for corrosion damaged slab-on-girder bridge columns using simplified nonlinear finite element analysis. PhD. Thesis, Dept. of Civil Engineering, University of Ottawa, Ottawa, Canada

Mohammed A, Almansour H, Martín-Pérez B (2012) State-of-the-art in nonlinear modeling of concrete frame structures under the combined effect of ultimate loading and reinforcement corrosion. In:
CSCE 3rd international structural specialty conference, Edmonton, Alberta, 6-9 June 2012

Mohammed A, Almansour H, Martín-Pérez B (2014) Evaluation of dynamic deformations of slab-on-girder bridge under moving truck with corrosion-damaged columns. Eng Struct 66:159-172

Oyado M, Saito Y, Yasojima A, Kanakubo T (2007) Structural performance of corroded rc column under seismic load. In: First international workshop on performance, protection and strengthening of structures under extreme loading, Whistler, Canada

Rasheed H, Dinno K (1994a) An efficient nonlinear analysis of RS sections. Comput Struct 53(3):613-623

Rasheed H, Dinno K (1994b) An improved nonlinear analysis of reinforced concrete frames. Comput Struct 53(3):625-636

Rashidi M, Gibson P (2012) A methodology for bridge condition evaluation. J Civil Eng Archit 6(9):1149-1157

Rodríguez J, Ortega LM, Casal J (1996) Load bearing capacity of concrete columns with corroded reinforcement. Corrosion of reinforcement in concrete construction. Royal Society of Chemistry, London, pp 220-230

Yalcin C, Saatcioglu M (2000) Inelastic of reinforced concrete columns. Comput Struct 77(5):539-555

Yingang D, Leslie A, Chan A (2007) Impact of reinforcement corrosion on ductile behaviour of reinforced concrete beams. ACI Struct J 104(28):285-293

Publisher's Note Springer Nature remains neutral with regard to jurisdictional claims in published maps and institutional affiliations. 